\title{
Zolpidem Use Among Dormitory Students in Yazd, Iran
}

\author{
Mohammad Amin Afshoon (iD) ${ }^{1}$, Saeed Hosseini (iD) ${ }^{1}$, Narjes Hazar (iD) ${ }^{2,}$, , Mahmood Vakili (iD) ${ }^{2}$ and Vahid \\ Rahmanian (iD) ${ }^{3}$ \\ ${ }^{1}$ School of Medicine, Shahid Sadoughi University of Medical Sciences, Yazd, IR Iran \\ ${ }^{2}$ Health Monitoring Research Center, School of Medicine, Shahid Sadoughi University of Medical Sciences, Yazd, IR Iran \\ ${ }^{3}$ Research Center for Social Determinants of Health, Jahrom University of Medical Sciences, Jahrom, IR Iran \\ "Corresponding author: Health Monitoring Research Center, School of Medicine, Shahid Sadoughi University of Medical Sciences, Yazd, Iran. Email: narjeshazar@yahoo.com
}

Received 2019 December 10; Revised 2020 January 29; Accepted 2020 February 03.

Keywords: Zolpidem, Substance-Related Disorders, Students, Dormitory, IR Iran

\section{Dear Editor,}

Zolpidem is a nonbenzodiazepine hypnotic agent that was accepted for a short-term treatment course of insomnia (1). This drug could be used for short-time relaxation before surgery. Meanwhile, because of its relaxant effect, it is used for sleep disturbance, especially initiating sleep, as the effect starts in 15 minutes after consumption. But, if the person does not intentionally sleep after usage, he/she may experience visual or auditory hallucinations that will be pleasing to the person; it may be less likely to take dangerous actions during the hallucination due to blood pressure drop and lethargy (2).

Due to the less effect of zolpidem on the sleep pattern and cognition than benzodiazepines, the tendency to use this drug is increasing, especially among college students (3). According to some reports, the prescription and usage of this substance have experienced increasing trends during the last two decades (4). However, there is no precise information about zolpidem arbitrary use, but given some evidence on the increasing use and trend of zolpidem abuse in the world, it seems that arbitrary consumption is increasing in the world and it may have increased in Iran, as well.

This cross-sectional study was performed among 573 college students who were residents of dormitories affiliated to Shahid Sadoughi University of Medical Sciences, Yazd, Iran, in the academic year 2017-2018. We used a stratified sampling method. Data were analyzed using SPSS version 18 software.

In our study, 283 (49.4\%) participants were male. Zolpidem was used by $74(12.9 \%)$ students and it was self-administered in $61(10.6 \%)$ ones. Zolpidem selfadministration was more prevalent among males, students who had employed mothers, smokers, opioid consumers, and Ritalin, propranolol, and tramadol users $(\mathrm{P}<0.05)$ (Table 1$)$.

Moreover, 35 out of 61 (57.3\%) zolpidem arbitrary consumers declared that they prepared the drug from the drugstore and the rest prepared it from other sources. In addition, 46 of 74 (62.16\%) zolpidem users had experienced some side effects including a headache, visual and auditory hallucinations, amnesia, and confusion. The stated reasons for zolpidem use were sleep regulation in most users (56.8\%) and experiencing hallucination, euphoria, and pleasure $(17.5 \%)$.

We found that the frequency of zolpidem use was $12.9 \%$ among college students who were residents of dormitories in which, $2.3 \%$ was prescribed by a medical practitioner and the rest was self-administered.

Based on searching the literature, there was no study on zolpidem abuse among populations in Iran and the studies were limited to some case reports $(5,6)$. The study in this field in the world is also very limited. According to the information derived from the French Centre for Evaluation and Information on Pharmacodependence (CEIP) in 2006, the prevalence of drug addicts who misused zolpidem increased from less than 1\% in 1998 to near 2\% in 1999 and $4 \%$ in 2001 (7). Meanwhile, this research showed that until 1998, all the mentioned zolpidem misusers had access to the drug through physician prescription but the method of access to the drug has changed to street dealing among 15\% - 20\% since 2001. In the present study, 35 of $61(57.3 \%)$ zolpidem arbitrary consumers declared that they prepared the drug from drugstores and the rest prepared it from other sources. Even though preparing a licit drug from sources other than pharmacy is not acceptable, the possibility of supplying it from a pharmacy without prescription is wrong and worrisome and the pharmacists 


\begin{tabular}{|c|c|c|c|}
\hline \multirow{2}{*}{ Variable } & \multicolumn{2}{|c|}{ Arbitrary, No. (\%) } & \multirow{2}{*}{ P Value } \\
\hline & Yes & No & \\
\hline Gender & & & 0.001 \\
\hline Male & $234(82.7)$ & $49(17.3)$ & \\
\hline Female & $278(95.9)$ & $12(4.1)$ & \\
\hline Grade & & & 0.146 \\
\hline Bachelor & $146(94.2)$ & $9(5.8)$ & \\
\hline Master of Science & $61(88.4)$ & $8(11.6)$ & \\
\hline General practitioner & $289(87.3)$ & $42(12.7)$ & \\
\hline Ph.D. & $14(87.5)$ & $2(12.5)$ & \\
\hline College & & & 0.36 \\
\hline Medicine & $199(88.4)$ & $26(11.6)$ & \\
\hline Pharmacology & $50(87.7)$ & $7(12.3)$ & \\
\hline Dentistry & $39(83)$ & $8(17)$ & \\
\hline Health & $99(91.7)$ & $9(8.3)$ & \\
\hline Nursing & $50(96.2)$ & $2(3.8)$ & \\
\hline Paramedicine & $73(98)$ & $9(11)$ & \\
\hline Father's education & & & 0.2 \\
\hline High school & $78(94)$ & $5(6)$ & \\
\hline Diploma & $137(86.2)$ & $22(13.8)$ & \\
\hline Associate Degree & $36(94.7)$ & $2(5.3)$ & \\
\hline Bachelor & $165(89.7)$ & $19(10.3)$ & \\
\hline Master of Science & $54(85.7)$ & $9(14.3)$ & \\
\hline Ph.D. & $28(96.6)$ & $1(3.4)$ & \\
\hline Mother's education & & & 0.53 \\
\hline High school & $129(92.1)$ & $11(7.9)$ & \\
\hline Diploma & $169(89.9)$ & $21(11.1)$ & \\
\hline Associate Degree & $28(93.3)$ & $2(6.7)$ & \\
\hline Bachelor & $132(86.3)$ & $21(13.7)$ & \\
\hline Master of Science & $28(93.3)$ & $2(6.7)$ & \\
\hline Ph.D. & $10(83.3)$ & $2(16.7)$ & \\
\hline Father's occupation & & & 0.6 \\
\hline Governmental & $229(90.9)$ & $23(9.1)$ & \\
\hline Non-governmental & $176(88)$ & $24(12)$ & \\
\hline Others & $95(88.8)$ & $12(11.2)$ & \\
\hline Mother's occupation & & & 0.008 \\
\hline Housewife & $344(90.8)$ & $35(9.2)$ & \\
\hline Governmental & $131(89.1)$ & $16(10.9)$ & \\
\hline Others & $25(73.5)$ & $6(26.5)$ & \\
\hline Smoking & & & 0.001 \\
\hline Yes & $33(51.6)$ & $31(48.4)$ & \\
\hline No & $479(94.1)$ & $30(5.9)$ & \\
\hline Addiction & & & 0.001 \\
\hline Yes & $9(45)$ & $11(55)$ & \\
\hline No & $503(91)$ & $50(9)$ & \\
\hline Ritalin use & & & 0.001 \\
\hline Yes & $17(47.2)$ & $19(52.8)$ & \\
\hline No & $495(92.2)$ & $42(7.8)$ & \\
\hline Tramadol use & & & 0.001 \\
\hline Yes & $9(47.4)$ & $10(52.6)$ & \\
\hline No & $503(90.8)$ & $51(9.2)$ & \\
\hline Inderal use & & & 0.014 \\
\hline Yes & $24(75)$ & $8(25)$ & \\
\hline No & $488(90.2)$ & $53(9.8)$ & \\
\hline
\end{tabular}


must be warned on this issue.

Hsu et al. in a study in 2014 investigated the top five most abused drugs in Taiwan, based on the reports of medical centers during 2002 - 2011. They found zolpidem as the fifth drug to be abused in the mentioned period (8). Based on the results of the mentioned and current studies, the tendency to zolpidem abuse is increasing in some populations and it should be taken into timely consideration and proper action.

Another finding of the present study showed higher zolpidem abuse among male than female students. This finding can be due to the fact that men are more risk-takers and sensation seekers than women.

In this study, the most common reason for using zolpidem was sleep regulation (56.8\%). In other words, the most important reason for the study participants to take zolpidem was sleep disturbance due to residing in the dormitory. The noise in the dormitory, the roommates, and other special conditions surrounding the dormitory can cause people to be significantly sleep-disturbed in this environment. This sleep disorder may have a major impact on the quality of day-to-day life and education of students, making them more likely to take arbitrary sleep medications, including zolpidem, which has fewer side effects than benzodiazepines.

Research shows that one of the most important reasons for people to take medication is to feel good (9). The euphoria created by drugs initially causes people to take them. But the problem is that after a while, not only the person does not feel the same feeling as before, but he/she is forced to take the drug just to return to normal. The results from some studies have shown that zolpidem is one of the medications that causes euphoria but does not appear to be addictive and its abrupt discontinuation does not cause withdrawal symptoms when used at a regular dose $(6,10)$. However, as the results of the present study showed, about two-thirds of students taking zolpidem had drug side effects. Moreover, withdrawal symptoms such as anxiety, tremor, palpitation, or seizure have been seen in some people after abrupt discontinuation of zolpidem, especially in high dose and long-term use, and the number of cases reported today is increasing (6). For this reason, students and other people should be aware of potential side effects and refrain from taking this drug unless considering medical considerations. In conclusion, it is necessary to take measures in the self-treatment of students, especially in taking drugs without a doctor's prescription, and education on this issue seems necessary.

A limitation of this study is that it was done on medical students living in dormitories; this can influence the results of this study, as there are differences in students living in dormitories in terms of socioeconomic status, cul- tural and even conditions in dormitories and other factors in comparison with other students who do not choose dormitories as their residency places.

\section{Acknowledgments}

This study was derived from an MD thesis at Shahid Sadoughi University of Medical Sciences, Yazd, Iran. We, hereby, sincerely appreciate all students who collaborated in this study.

\section{Footnotes}

Authors' Contribution: Study concept and design: Mohammad Amin Afshoon, Saeed Hosseini, and Narjes Hazar; acquisition of data: Mohammad Amin Afshoon, and Narjes Hazar; analysis and interpretation of data: Vahid Rahmanian, Saeed Hosseini, and Narjes Hazar; drafting of the manuscript: Vahid Rahmanian, Saeed Hosseini, and Narjes Hazar; critical revision of the manuscript for important intellectual content: Vahid Rahmanian, Saeed Hosseini, Narjes Hazar, and Mahmood Vakili; statistical analysis: Mohammad Amin Afshoon, Saeed Hosseini, and Mahmood Vakili; administrative, technical, and material support: Mohammad Amin Afshoon, Saeed Hosseini, Narjes Hazar, Mahmood Vakili, and Vahid Rahmanian; study supervision: Narjes Hazar.

Conflict of Interests: The authors declare that there is no conflict of interest.

Ethical Approval: This study was conducted in accordance with the Declaration of Helsinki, and the protocol was approved by the Ethics Committee of Yazd University of Medical Sciences (project identification code: IR.SSU.MEDICINE.REC.1397.070).

Funding/Support: This project was financially supported by the Vice-Chancellor for Research of Shahid Sadoughi University of Medical Sciences.

\section{References}

1. Moore TJ, Mattison DR. Assessment of patterns of potentially unsafe use of zolpidem. JAMA Intern Med. 2018;178(9):1275-7. doi: 10.1001/jamainternmed.2018.3031. [PubMed: 30014137]. [PubMed Central: PMC6583219].

2. Kesselheim AS, Sinha MS, Campbell EG, Schneeweiss S, Rausch P, Lappin BM, et al. Multimodal analysis of FDA drug safety communications: Lessons from zolpidem. Drug Saf. 2019;42(11):1287-95. doi: 10.1007/s40264-019-00849-8. [PubMed: 31302895].

3. Netzel CL, Abd-Elsayed A. Benzodiazepines. Pain. Springer; 2019. p. 289-92. doi: 10.1007/978-3-319-99124-5_63. 
4. Jang Y, Song I, Oh IS, Shin JY. Twelve-year trend in the use of zolpidem and physicians' non-compliance with recommended duration: A Korean national health insurance database study. Eur J Clin Pharmacol. 2019;75(1):109-17. doi: 10.1007/s00228-018-2563-9. [PubMed: 30280207].

5. Mortaz Hejri S, Faizi M, Babaeian M. Zolpidem-induced suicide attempt: A case report. Daru. 2013;21(1):77. doi: 10.1186/2008-2231-21-77. [PubMed: 24359886]. [PubMed Central: PMC3878174].

6. Haji Seyed Javadi SA, Hajiali F, Nassiri-Asl M. Zolpidem dependency and withdrawal seizure: A case report study. Iran Red Crescent Med J. 2014;16(11). e19926. doi: 10.5812/ircmj.19926. [PubMed: 25763219]. [PubMed Central: PMC4329938].

7. Victorri-Vigneau C, Dailly E, Veyrac G, Jolliet P. Evidence of zolpidem abuse and dependence: Results of the French Centre for Evaluation and Information on Pharmacodependence (CEIP) network survey. $\mathrm{Br} J$ Clin Pharmacol. 2007;64(2):198-209. doi: 10.1111/j.1365-2125.2007.02861.x. [PubMed: 17324242]. [PubMed Central: PMC2000636].

8. Hsu J, Lin JJ, Tsay WI. Analysis of drug abuse data reported by medical institutions in Taiwan from 2002 to 2011. J Food Drug Anal. 2014;22(2):169-77. doi: 10.1016/j.jfda.2014.01.019.

9. Rahimi Pordanjani S, Fallah Zadeh H, Mousavi M, Khazaei S, Sohrabivafa M, Momenabadi V, et al. Prevalence and reasons for psychoactive drugs use among university students of medical sciences in Yazd, Iran. Iran J Psychiatr Behav Sci. 2018;12(1). e9384. doi:10.5812/ijpbs.9384.

10. Holm KJ, Goa KL. Zolpidem: An update of its pharmacology, therapeutic efficacy and tolerability in the treatment of insomnia. Drugs. 2000;59(4):865-89. doi: 10.2165/00003495-200059040-00014. [PubMed: 10804040]. 